\title{
Analyzing Due Process in the Workplace
}

\author{
ELIHU M. GERSON AND SUSAN LEIGH STAR
}

Tremont Research Institute

Every office is an open system, and the products of office work are the result of decentralized negotiations. Changing patterns of task organization and alliance inevitably give rise to inconsistent knowledge bases and procedures. This implies that there are no globally correct answers to problems addressed by OISs. Rather, systems must deal with multiple competing, possibly irreconcilable, solutions. Articulating alternative solutions is the problem of due process. This problem and its consequences are illustrated by a case study of a rate-setting group in a large health insurance firm.

There is no formal solution to the problem of due process. But it must be solved in practice if distributed intelligent OISs are to be developed. We propose an alternative approach based on the work of social scientists concerned with analyzing analogous problems in human organization. Solution of the due process problem hinges on developing local closures to the problem faced by an organization. This means analyzing (a) local, tacit knowledge and its transfer ability; (b) articulation work, that is, reconciling incommensurate assumptions and procedures.

Categories and Subject Descriptors: H.1.1 [Models and Principles]: Systems and Information Theory; I.2.0 [Artificial Intelligence]: General; I.2.4 [Artificial Intelligence]: Knowledge Representation Formalisms and Methods; K.6.1 [Management of Computing and Information Systems]: Project and People Management-systems analysis and design; systems development; K.6.4 [Management of Computing and Information Systems]: System Management-centralization/ decentralization

General Terms: Design, Human Factors

\section{INTRODUCTION}

No representation of the world is either complete or permanent [11]. Rather, any description is a snapshot of historical processes in which differing viewpoints, local contingencies, and multiple interests have been temporarily reconciled [ 3 and 13]. Kent [23] has provided a detailed analysis of the difficulties encountered even with well-structured information and an unproblematic organizational context. But, as any office manager can tell you, even apparently simple pieces of information such as entries on fixed forms are the result of many negotiations and struggles. These may include ad hoc decisions by clerks, responses to patron complaints, the organization's policy decisions, the rules of regulatory bodies, and the limits of the local database management system. In order to create adequate representations then, office workers must somehow reconcile multiple

\footnotetext{
Authors' address: Tremont Research Institute, 458 29th Street, San Francisco, CA 94131.

Permission to copy without fee all or part of this material is granted provided that the copies are not made or distributed for direct commercial advantage, the ACM copyright notice and the title of the publication and its datc appear, and notice is given that copying is by permission of the Association for Computing Machinery. To copy otherwise, or to republish, requires a fee and/or specific permission.
}

(C) 1986 ACM 0734-2071/86/0700-0257 $\$ 00.75$

ACM Transactions on Office Information Systems, Vol. 4, No. 3, July 1986, Pages 257-270. 
viewpoints with inconsistent and evolving knowledge bases. Since no centralized authority can possibly anticipate all the contingencies that might arise locally, office workers always have some discretion in deciding how this reconciliation is to be accomplished [10 and 17].

In the terminology developed by Hewitt and his associates to describe open systems $[1,16,18$, and 19], workplace information systems thus require due process. In the office, the due process problem is this: How can we assure that information systems make adequate provision for recognizing, weighing, and evaluating alternatives from conflicting sources? We call the work of ensuring due process articulation [4, 7, and 50]. Articulation consists of all the tasks needed to coordinate a particular task, including scheduling subtasks, recovering from errors, and assembling resources.

Articulation is a necessary part of due process because the definition of adequate provision shifts according to local circumstances. No matter how detailed the requirements are, they must be aligned with or tailored to a set of implementation conditions that cannot be fully specified ahead of time.

Standardized representations of office work and its products, as captured in forms, diagrams, databases, or narrative text, are thus the result of articulation, the local adjustments that made the work possible in practice. An adequate conceptual basis for the design and implementation of office information systems hence requires understanding the articulation by which these representations are created.

Without an understanding of articulation, the gap between requirements and the actual work process in the office will remain inaccessible to analysis. That is, it will be possible to describe tasks in an idealized form but not to describe actual situations. When the articulation of the work is deleted in representations of that work, the resulting task descriptions can only be uneasily superimposed on the flow of work. The current proliferation of "methodologies" to describe work flow in the office reflects this state of affairs.

It will always be the case that in any local situation actors "fiddle" or shift requirements in order to get their work done in the face of local contingencies. We argue here that such articulation is not extraneous to requirements analysis, but central to it. In order to understand more about articulation both practically and theoretically, we need to have detailed empirical organizational analysis. In this paper we present an empirical case of an office situation, emphasizing the articulation-requirements-representation dynamics. We follow this case with a discussion of the implications for office information systems analysis and a discussion of the problems of due process in open systems considered more broadly.

\section{A CASE STUDY: PROVIDER PAYMENT RATES AT "PACIFIC HEALTH UNDERWRITERS COMPANY"}

Let us examine some of the implications of the centrality of articulation for office information systems by considering a case study. The "Pacific Health Underwriters Company" (PHU) is a large insurance company that provides health insurance to both individuals and groups. Paying health care professionals, ACM Transactions on Office Information Systems, Vol. 4, No. 3, July 1986. 
(called "providers") is an important task for the central office. Providers are paid on a fee-for-service basis: Every service provided to patients is billed and paid separately. PHU has guidelines that describe all the services provided by professionals, together with the price which PHU pays for each service. The company maintains a unit which writes these guidelines.

Superficially, creating and keeping track of such guidelines represent a straightforward database management task. A system to support this work should contain information on types of illnesses and procedures used to treat them, and match those diseases and procedures with reimbursement codes that indicate how much providers will be paid. But due process problems make this work enormously complex.

\subsection{Different Viewpoints about Procedure Codes}

The problems arise in part because different groups involved in the process have different viewpoints about how to code medical procedures. The different viewpoints must be reconciled into a single representation, a manual of procedure codes and reimbursement rates. Different viewpoints mean that creating a common representation will generate articulation problems as the object is fitted into the local circumstances. The different groups involved here and their viewpoints are:

(1) Doctors and other providers often want a very detailed coding scheme so they will be reimbursed for each separate procedure. They also want codes to represent current practice and costs (which means frequent updates) and to be easily billable and quickly paid.

(2) Representatives for large customer groups may want the most inclusive benefit definitions, so that coverage will be of greater value for clients. This implies relatively broad or coarse-grained categories.

(3) PHU Operations includes the claims payment and adjustment, customer service, and policy units. These units pay claims, explain payments, and calculate what gets paid and how to calculate it. They want the simplest possible structure of codes and procedures.

(4) PHU Marketing, because it sells to groups, wants a relatively fine-grained category scheme. Whether or not groups will accept a particular form of insurance may depend on the details of the categorization.

(5) PHU Medical Review checks calculated payments and reviews nonstandard claims for payment. Claims are rejected if they are not in conformity with technical standards established by outside agencies. Often, there is great technical ambiguity in determining what diagnostic categories can plausibly be associated with which treatment categories. Medical reviewers naturally wish to eliminate this ambiguity.

(6) PHU New Products Division develops new kinds of policies and new payment mechanisms. It is thus often concerned to have new procedure codes developed and used in the system.

(7) PHU Data Processing wants relatively few and simple configurations of contracts, policies, codes, and payment arrangements in order to make tasks 
easier. PHUs software and hardware facilities are obsolete, badly maintained, overloaded, and cannot handle the complexity of a fine-grained, complex coding scheme. The facilities are devoted almost entirely to large-scale transaction processing (often in batch mode). No office automation functions are supported.

(8) PHU legal advisers insist that codes be consistent, clear to consumers, and legally defensible. Thus, the legal branch of the company often vetoes particular coding revisions that would make the scheme broader or narrower.

(9) PHU Research compares rates of payment under different circumstances. It is concerned with establishing consistency among payment rationales and procedures.

The guidelines are issued in the form of a large annual volume containing prices and codes; the book is typically well over 1000 pages in length. Prices vary across customer groups and geographical regions. For example, a very large subscriber group can negotiate discount rates for certain procedures. Providers from a region with a higher cost of living may get reimbursed at a higher rate than those from another region where costs are lower. Finally, procedures that require higher degrees of skill and complex support facilities are reimbursed at higher rates than those that do not. The codes and coding schemes that are generated are thus complex and reflect many aspects of medical work organization as well as Pacific's internal functions. Some of the considerations involved in arriving at codes include the following:

(1) Changes in procedure definitions. Changes in technology or medical definition of disease conditions can lead to new codes, dropped codes, or combined codes.

(2) Changes in payment for a given code. These may arise from splitting a code by provider type. For example, "psychotherapy" now covers licensed providers including psychiatrists, licensed marriage and family counselors, psychologists, and social workers. This category may be split up, with a separate code for each kind of therapist.

(3) Changes in relative value. These price changes are made as a result of research at Pacific. They reflect statistical trends in a given provider group's fees. They may also reflect known changes in practice.

(4) Contract coverage. Some groups will not pay for certain services, and others require coverage under special contract terms. For example, many group contracts will not cover cosmetic surgery, but a local actors' union contract does provide such coverage. Such differences must be accounted for and mediated by Pacific.

\subsection{Sources of Change and Conflict in Coding}

Changes in codes or coding schemes come from many sources, each raising due process issues. Provider groups may press for changes in relative price value for procedures as they make professional changes. Changes made in relative values may in turn cause contract problems or revisions, partly because of data processing difficulties. Long-term contracts also make for problems. For example, a contract may reflect prices set in 1974, which have since changed. But in order 
to arrive at a code and price for a new procedure (e.g., Magnetic Resonance Imaging), Pacific must keep records for 1964, 1974, and current pricing, in order to extrapolate back to arrive at a fair rate for current comparable procedures.

Different consequences for different groups derive from narrow and broad coding schemes. For example, if every little part of a procedure is separately coded and reimbursed, then health care providers can bill the insurance company for each step of a procedure and make more money. Such fine-grained coding makes the data processing task at the insurance company office much more time consuming and unwieldy. Often, providers of care offer to bill Pacific a single all-inclusive fee for a set of services. This may lead to other data processing problems, in structuring the databases and in tracking previous claims that should be retroactively included in the all-inclusive fee.

The procedure coding derives from Pacific's understanding of the relationship between disease, diagnosis, and procedures. Thus, a diagnosis of the disease mumps may result in a delivery of service with a procedure code such as 0001 : Administer Injection of Gamma Globulin. Diagnoses may be broken down more narrowly, for example, Childhood Mumps and Adult Mumps or Green San Francisco-strain Mumps and Blue Boston-strain Mumps.

New diagnostic categories (such as the Acquired Immune Deficiency Syndrome) often mean changes in procedure codes. Here again, a source of conflicting viewpoints arises. Medical opinion is never in total agreement about diagnostic entities; thus, choosing a diagnostic category means selecting and betting on medical expertise [44]. PHU's policy is that this selection should be representative of mainstream opinion-a problematic concept, to say the least.

New medical technologies are another source of change in procedure codes. For example, when the Magnetic Resonance Image scanner became available for clinical use, new procedure codes had to be created and disseminated to providers. This becomes a source of potential conflict if different parts of the medical community or government agencies disagree about the status of the technology.

Further, until there is general acceptance of a procedure, codes may be idiosyncratic and vary from insurer to insurer, making data collection and reimbursement difficult. Some attempt may be made to value a new procedure as a percentage of the professional effort involved in an older, known, similar procedure.

Changes in medical work organization are a third source of continual evolution in the procedure coding scheme. For example, when a hospital adds a new burn unit to its facilities, procedures are no longer coded as part of a general trauma service, but receive special new codes. Conflict can arise here if the insurance company believes that the procedure should be allocated to one part of the organization and the providers believe it should be allocated to another.

Mobility of groups of different specialists within medical practice can lead to code development and changing emphasis. Anesthesiologists, for example, are now fighting for a very different structure for coding schemes, one based on body system/area rather than on anesthesia as a technical adjunct to a surgery procedure. Another example is provided by a recent controversy about "cognitive" versus hands-on procedures. Some providers want the relative weight of evaluative services increased; this is in opposition to the concerns of surgeons, for example, who get paid primarily for manual work. 
The general situation here is that changes in medical work organization and technology, as well as new insurance products, force continual recategorization and repricing of procedures. Different and mismatching categories mean that conflicting viewpoints must be reconciled in order for the procedure codes to be made uniform. This articulation is central to the development of coding schemes.

\subsection{A "Due Process" Unit}

The resolution of conflicting viewpoints and continually evolving, inconsistent knowledge bases is handled by a specialized unit at Pacific. Let us call it the Process Policy Unit (PPU). This group of five people is in charge of updating procedure codes, aligning policy decisions about procedures with data processing capabilities, and producing the annual volume of procedure guidelines. The guidelines are the "bottom line" for the group, since many other operations at PHU depend on them. The PPU is not a centralized authority for information processing; it is not empowered to make yes-or-no decisions about changing procedure codes in an absolute fashion. Rather, it articulates claims and information from different groups and sources of change, proposing compromises in coding a procedure that, when accepted, are incorporated into the next edition of the guidelines.

Articulating the several forms of veto-or discretion-exercised by the interested players is thus the major job of the PPU. The unit has several strategies for obtaining agreements via its articulation work:

(1) Skepticism. When one group begins to agitate for a change in procedures, the PPU evaluates the evidence and arguments in the light of PHU's overall policies and commitments. Formal skepticism is one way to force clarification of arguments for a position. In a recent example, providers at specialty hospitals formed a group and argued that they should be paid more than general hospitals for certain procedures because they had more advanced equipment and skills. An internal skeptic from Pacific argued that the claimed differentials did not exist and that, in any case, they should be paid less, because their costs for providing such services were lower owing to economies of scale. The immediate compromise was a study of actual procedures in these hospitals in order to identify specific actual differences.

(2) Arbitrating trade-offs and bargaining between interest groups. The PPU occasionally arbitrates trade-offs and hargains between interest groups. For example, a new part of Pacific, previously an independent company, had operated with a payment structure which differed from the central company. When it joined Pacific, it became necessary to develop an interim update structure with elements from both companies.

(3) Local knowledge from the unit's history. The PPU itself has accumulated quite a bit of specialized experience with the various concerns involved in producing the guideline volume. This local knowledge of precedent is routinely used to evaluate, explain, and justify proposed courses of action. In other words, the PPU brings local knowledge of past compromises into making guidelines.

(4) Discretion employed by the unit itself in making representations. The PPU itself exercises some discretion about how procedure codes will be managed. This 
includes the way in which competing interests are represented to senior executives. Emphasizing certain kinds of information and deemphasizing others can result in changes in policy as policymakers review claims from the different interest groups.

(5) The need for confidentiality. Pacific has an explicit internal policy not to document internal decisions, or to document them idiosyncratically so that decisions will not leak out to providers and create or exacerbate legal liabilities. Thus, local knowledge and discretion of staff members in making decisions and assessing importance are a critical part of their due process work.

In sum, the PPU uses a repertoire of strategies to reconcile viewpoints, decompose the fuzzy and complex problems of procedure coding, and bring temporary local closure to the open information system in order to produce its single representation, the guideline volume. Included in this repertoire are the use of skeptics, arbitrating trade-offs, use of local knowledge, and discretion in making representations.

\section{DUE PROCESS IN OPEN SYSTEMS}

The PPU at PHU illustrates the salient points that define open systems: evolutionary change, lack of central authority, and perpetual inconsistency among knowledge bases [17]. These characteristics generate the due process problem. Traditionally, finding solutions to information systems problems has been framed as one of arriving at the "correct answer" via algorithmic procedures. Thus, we might conceive of specifying or modifying the procedure payment categories at PHU as a straightforward problem of specifying appropriate data formats.

However, in complex open systems, the procedures by which one solves problems themselves become objects of adjudication. Because there are independent rationales for answers and because there is no central control mechanism, there is no way of determining a globally correct answer. Rather, there are multiple, possibly inconsistent, competing answers, none of which has a unique claim to validity. The PPU does not have a privileged overview or control over due process. Rather, its existence as a unit and the articulation it provides exemplify general organizational processes.

The evolutionary character of open systems hence requires negotiation between components on the basis of needs and estimates that are locally generated [17, 18,19 , and 47]. The inherent necessity for negotiation, rather than algorithmic calculation, in order to arrive at an answer is the due process problem.

The due process problem can arise at any level of organizational scale. Even relatively centralized organizational units must evolve, negotiate, and remain subject to local constraints. For example, at PHU there is one data processing department that operates a small number of mainframes, each handling a few well-separated tasks. At that level of organization, then, there is a centralized authority, and definitive decisions can be made when competing priorities and incompatibilities arise. But this authority extends only to the day-to-day operations of information systems already in place. The Data Processing (DP) department can decide to run one application system before another, or it can refuse to provide a data tape formatted in a way that is incompatible with the current 
database structure. It thus exercises a de facto veto over some aspects of the payment procedure, which simply shifts due process problems to the level of interdepartmental relations. Over the long term, the DP department cannot control the emergence of new (and incompatible) systems designed to service specialized needs. New government regulations and marketplace pressures mean that PHU must be able to modify its payment procedures and reconcile incompatibilities sooner or later.

The continuing development of computing technologies over the next few years adds another dimension to this problem. Eventually, the centralized data processing system at PHU will evolve into one using many computers linked by some form of network. It is certain that the network will not be wholly contained within PHU's organizational boundaries. "Contracting out" part of the data processing load is under active consideration by PHU's management, and providers are rapidly acquiring their own systems and pressing for the capacity to hook up directly with PHU's. The DP department's de facto veto over certain kinds of operation will go away, and due process problems that are now handled at the interdepartmental level will become part of the day-to-day operations of the networked system. PHU is not alone in confronting this situation. The continuing drop in computing costs and the corresponding increases in computing power mean that every organization can expect a similar set of arrangements to evolve.

In short, due process problems will become intrinsic to the organization of information systems, as these systems become more and more like social organizations in their own right (diffuse, evolving, and decentralized, with multiple viewpoints). Consider a distributed system with no central authority. Even lowlevel system services such as access to peripherals become due process problems in such situations, since conflicting claims of arrival time in a system in which arrival sequence is not guaranteed require adjudication in order to serialize actions [20]. At the organizational level on the other hand, the local expertise and knowledge of designers and users generates system requirements and commitments to particular software and implementation strategies. As these interact across organizational boundaries, means must be found to translate from locale to locale and to reconcile conflicting claims and commitments.

Given that there may be no globally correct answer, then how does one pick the best available answer under local circumstances? At what point do actors decide that enough evidence of the right sort from the relevant domains has been collected? Faced with two incompatible expert answers, what procedures do they use? Should they retrace the decision tree and look at methods used? Should they use a previously selected algorithm? At present, there is no clear solution to the problem of due process issues in the design of highly parallel open computing systems (Hewitt, personal communication). And, as open systems are expanded beyond the laboratory prototype stages and become distributed through and among complex organizations, the problem will become increasingly urgent.

The assumptions of traditional, algorithmic approaches in the information sciences are not adequate to deal with the due process problem. A different approach is thus necessary. The problem of due process in various forms has always been at the heart of social science research. It thus seems a reasonable strategy to draw upon this accumulated expertise in formulating approaches to 
the due process problem as it appears in information systems. In 1977, for example, Hewitt drew on the metaphor of the scientific community as an aid to conceptualizing systems that have no central authority, but which must nonetheless arrive at reliable answers to complex problems [15]. This metaphor was later elaborated to support conceptualization of the forerunners of the apiary architecture [27]. This approach led to a series of studies of scientific work organization [10, 12, 39-43, and 45].

Our approach to analysis of due process in open systems rests on a tradition of research on the professions and technical work organization (e.g., [2, 3, 5, 8-10, 21, 24-26, 34-36, 46, 48, and 50]). From this point of view, the due process problem consists of two aspects: understanding the role of local knowledge and understanding the work of articulating all the contingencies that go into solving a problem.

\subsection{Local Knowledge and Practice}

Many of the procedures that organizations and professionals use to solve problems arise from their historical experience and are peculiar to local circumstances. Much of the knowledge embedded in such practices is tacit [33], not codified, and often not codifiable. Schon's description of reflective practice outlines many aspects of this tacit local knowledge [37]: the ability to identify consequences of informal or tacit inconsistencies; the ability to describe and/or identify unpredictable interactions; incorporation of others' (e.g., users') definitions of the local situation in planning work and assessing quality of results; progressive refinement of problem definitions and strategies as new information and capacities appear.

Similarly, Simon [38] has noted that the ability to learn to articulate multiple ill-structured problems is a sign of the "professional maturity" of the expert. But experts always work with others in complex organizational contexts. Our approach differs from Simon's, and from that of the designers of rule-based expert systems who codify expert knowledge (this work is summarized in [14]). These approaches seek to capture the process by which the single expert makes substantive or technical decisions. But experts do not work in isolation; they must coordinate with one another. In the PHU study, we saw that interorganizational coordination between such local systems routinely relies on such tacit knowledge, often built up over many years. The resulting representations thus contain much articulation history.

From this perspective, and especially in the conceptualization and design of open systems, it is the transferability of knowledge that is important. To the degree to which articulation is tacit and deleted from representations, requirements developed from those representations will be inadequate for local contingencies.

For example, when individual "wizards" become indispensable in organizations, they come to hold a great deal of influence through their tacit knowledge. The fact that their knowledge is privately held greatly shortens organizational memory; when the wizards leave, local knowledge leaves with them. The tacit nature of their knowledge makes it difficult to pass on. Such wizards are familiar to every office as computer room managers who are the only ones who can coax the system into functioning, or the crack secretary who "really runs the place." Such wizards are extreme examples of a ubiquitous phenomenon: tacit local knowledge 
that cannot be represented in a transferable fashion. An analogy in information systems is with the use of clever programming tricks that take advantage of specialized quirks of machine architecture. The impact of such arrangements on distributed concurrent systems (human organization, computer-based, or both) is to create islands of specialized usage that make free transfer and reliable crosscontextual use of information highly problematic. It is the tacit nature of such arrangements, not their local limitations, that prevent accessibility.

The development of methods for describing and analyzing tacit local knowledge has been a major thrust of recent work in the sociology of science (e.g., $[6,28$, $29,30-32,40$, and 44]). Much of this work has sought to illuminate the processes by which local knowledge becomes incorporated into final products that are transmitted as scientific "facts." By observing transformations of information at various stages in the fact-making process, sociologists of science have developed good models of the ways in which tacit local knowledge is encapsulated into research results.

But this process is precisely what must be understood if adequate models of due process are to be developed in support of information science research. The packaging and transmission of scientific results is but one example of the packaging and distribution of any kind of information in an open system: Reliable interpretation requires that incompatibilities between the context of production and the context of use be recognizable and recoverable. Methods for analyzing due process means, in this perspective, explicit procedures for evaluating and reconciling incompatibilities among different bodies of tacit local knowledge. And this, in turn, means empirical analytical models of how information flows among the parts of an open system.

\subsection{Articulation}

Reconciling incommensurate assumptions and procedures in the absence of enforceable standards is the essence of articulation [4, 7, 49, and 50]. Articulation consists of all the tasks involved in assembling, scheduling, monitoring, and coordinating all of the steps necessary to complete a production task. This means carrying through a course of action despite local contingencies, unanticipated glitches, incommensurable opinions and beliefs, or inadequate knowledge of local circumstances.

Every real-world system is an open system: It is impossible, both in practice and in theory, to anticipate and provide for every contingency which might arise in carrying out a series of tasks. No formal description of a system (or plan for its work) can thus be complete. Moreover, there is no way of guaranteeing that some contingency arising in the world will not be inconsistent with a formal description or plan for the system. These two points apply to every system, whether it be a human social organization or an information system. Every realworld system thus requires articulation to deal with the unanticipated contingencies that arise. Articulation resolves these inconsistencies by packaging a compromise that "gets the job done," that is, that closes the system locally and temporarily so that work can go on. In sum, articulation is an organizational expression of due process.

The results of this work appear as workarounds or kludges, that is, misfits with the idealized representations of work that requirements have represented. ACM Transactions on Office Information Systems, Vol. 4, No. 3, July 1986. 
However inelegant, workarounds are necessary to meet local resource constraints, deadlines, configuration limitations, or a mix of technical capacities. Workarounds are often invisible when the end product of development is examined, nor do they necessarily appear in the documentation of the system [22]. Moreover, we typically find multiple workarounds which are themselves potentially in conflict (kludges upon kludges). Hence, the use of workarounds solves the due process problem only locally and temporarily. There is no way of guaranteeing that two workarounds, each adequate in its own local context, will not recursively prove to be incompatible in a larger context. Clearly, this process forms an infinite regress.

Nonetheless, real-world organizations do in fact solve their due process problems via articulation, and produce reasonably reliable results. PHU faces a continuing stream of articulation problems, none of which are ever definitively solved; there is always a new treatment, a new technology, a new diagnostic category, or a new specialty that raises compatibility issues. It thus contains all the fundamental characteristics of real-world open systems. On the one hand, there is no way of reaching a complete or consistent description of these systems or plan for them; an open system is irremediably open. On the other hand, every real-world system requires local closures so that its work may continue. The problem then, for constitutions no less than for information systems, is to develop ways of designing systems that continuously evaluate their own conditions, and restructure themselves as changing circumstances require different patterns of local closure.

\section{ANALYTICAL SUMMARY}

Many organizations do not create separate due process units to do the job of articulation. But the problems undertaken by the PPU at Pacific are familiar to anyone with even a casual acquaintance with workplace information systems. In designing information systems that will meet workplace requirements then, the following points are important:

(1) Multiple viewpoints in the office need to be represented by sophisticated, highly parallel information systems in order that technological limitations not make policy decisions tacitly by screening out viewpoints.

(2) No piece of information is simple. In the example above, even something so seemingly simple as what is a disease and how much does a treatment cost is enormously uncertain and complex.

(3) Every category represents a piece of history containing due process. For example, some PHU reviewers in the past had shown concern only about checking procedures of personal interest to them. This has meant that many codes had little attention devoted to them in review procedures. The PPU is thus obliged to review uses of all codes.

(4) No representation is complete. Negotiation about the representation of information means that not all viewpoints will be completely and severally represented in any one representation. Furthermore, evolving systems and asynchronous updates mean that as a representation is frozen in time, the knowledge base from which it is drawn is changing. Each representation is therefore incomplete. 
(5) Owing to the impact of new technologies and changes in work organization, information systems for workplaces cannot be designed ahead of time without knowing the empirical workplace situation [10]. They must be designed and maintained while they are in use.

(6) Because of the lack of omniscient decision making in workplaces, information systems cannot be designed independently of empirical knowledge of workplaces. Any representation of the workplace produced in order to help designers is biased; in order to accurately represent the open systems' properties of workplaces we should study them and incorporate tacit knowledge and articulation.

The articulation performed by organizations as they solve their due process problems thus represents a key design requirement for workplace information systems. To the extent that we are able to incorporate articulation into requirements, the more adequate the representation of open office systems becomes. Because representations have often obscured these processes, empirical analysis of workplaces is the basis of such design. And owing to the continually evolving, asynchronously updated nature of all real-world systems (human or machine), the results of these empirical analyses are themselves open.

\section{ACKNOWLEDGMENTS}

Howard S. Becker, M. S. Gerson, Carl Hewitt, Walt Scacchi, and Anselm Strauss have been very helpful in formulating the ideas presented here. We are grateful to our anonymous respondents at Pacific Health Underwriters for their generous assistance.

\section{REFERENCES}

1. Agha, G. A. Actors: A model of concurrent computation in distributed systems. Tech. Rep. 844, MIT Artificial Intelligence Laboratory, MIT Press, Cambridge, Mass., 1985.

2. Becker, H. S. Sociological Work. Aldine, Chicago, Ill., 1970.

3. Becker, H. S. Art Worlds. University of California Press, Berkeley, 1982.

4. Bendifallah, S., AND ScaCchi, W. Understanding software maintenance work. IEEE Trans. Softw. Eng., SE-131 (1987).

5. Bucher, R., and Stelling, J. Becoming Professional. Sage, Beverly Hills, Calif., 1977.

6. Collins, H. Changing Order: Replication and Induction in Scientific Practice. Sage, London, 1985.

7. Fujimcra, J. The construction of doable problems in cancer research. In Social Studies of Science, forthcoming.

8. Gasser, L. The social dynamics of routine computer use in complex organizations. Ph.D. dissertation, Dept. of Information and Computer Science, Univ. of California, Irvine, 1984.

9. Gerson, E. M. Scientific work and social worlds. Knowledge, 4 (1983), 357-377.

10. Gerson, E. M. Information systems in complex organizations: Challenges for research. Paper presented to the ACM, San Francisco, 1984.

11. Gerson, E. M. Data structures for sociological research. Tremont Tech. Rep., Tremont Research Institute, San Francisco, 1985.

12. Gerson, E. M., ANd Star, S. L. Practical reasoning: The plausibility of arguments. Report submitted to the MIT Artificial Intelligence Lab, 1984.

13. Gerson, E. M., And Star, S. L. Representation and re-representation in scientific work. Tremont Tech. Rep., Tremont Research Institute, San Francisco, 1985.

14. Hayes-Roth, F., Waterman, D. A., AND Lenat, D. B. (Eds.) Building Expert Systems. Addison-Wesley, Boston, 1983. 
15. HEwiTT, C. Viewing control structures as patterns of passing messages. Artif. Intell., 8,3 (1977), 323-364.

16. HewITT, C. Towards new foundations for intelligent systems. Submitted for publication.

17. Hewirt, C. The challenge of open systems. BYTE, 10 (April 1985), 223-242.

18. HewitT, C., AND DEJong, P. Analyzing the roles of descriptions and actions in open systems. In Proceedings of the National Conference on Artificial Intelligence (Washington, D.C., Aug.). AAAI, 1983, pp. 162-167.

19. Hewitt, C., AND DeJong, P. Open systems. In Conceptual Modelling, M. Brodie et al., Eds. Springer Verlag, New York, 1984, pp. 147-164.

20. Hewitt, C., Reinhardt, T., Agha, G., and AtTardi, G. Linguistic support of receptionists for shared resources. MIT Artificial Intelligence Memo 781, MIT Press, Cambridge, Mass., 1984.

21. Hughes, E. C. The Sociological Eye. Aldine, Chicago, 1970.

22. JazzaR, A., AND SCACCHI, W. Computer systems documentation: An unknown quantity. Submitted for publication.

23. Kent, W. Data and Reality. North Holland, Amsterdam, 1978.

24. KLing, R., AND Gerson, E. M. The social dynamics of technical innovation in the computing world. Symbolic Interaction, 1 (1978a), 132-146.

25. Kling, R., AND Gerson, E. M. Patterns of segmentation and intersection in the computing world. Symbolic Interaction, 1 (1978b), 24-43.

26. Kling, R., AND SCACCHI, W. The web of computing: Computing technology as social organization. Advances in Computers, 21 (1982), 3-85.

27. Kornfeld, W., AND HEwITT, C. The scientific community metaphor. IEEE Trans. Syst., Man Cybern., SMC-11 (1981), 24-33.

28. LATour, B. Visualization and cognition: Thinking with eyes and hands. In Knowledge and Society: Studies in the Sociology of Culture, Past and Present, H. Kucklick, Ed. Greenwich, Conn., JAI Press, forthcoming.

29. Latour, B., AND Woolgar, S. Laboratory Life. Sage, Beverly Hills, Calif., 1979.

30. LAw, J. Les textes and leur alliés. Culture Technique, 14 (1985), 59-69.

31. LAw, J. Technology, closure and heterogeneous engineering: The case of the portuguese expansion. In Pruceedings of the Workshop un New Develupments in the Sucial Sludy of Technology, T. Pinch and W. Bijker, Eds. Enschede, Holland, forthcoming.

32. LYNCH, M. Art and Artefact in Laboratory Science. Routledge and Kegan Paul, London, 1985.

33. Polanyi, M. Personal Knowledge: Towards a Post-Critical Philosophy. Harper \& Row, New York, 1958.

34. SCACCHI, W. Managing software engineering projects: A social analysis. IEEE Trans. Softw. Eng. $S E-10$ (1984), 49-59.

35. SCACCHI, W. The system factory approach to VLSI and software engineering. In Proceedings AFCET Second Software Engineering Conference (Nice, France). AFCET, 1984, pp. 349-359.

36. SCACCHI, W., GaSSER, L., AND Gerson, E. M. Problems and strategies in organizing computeraided design work. In Proceedings of the IEEE International Conference on Computer-Aided Design (San Jose, Calif., Sept.). IEEE, New York, 1983, pp. 166-167.

37. Schon, D. The Reflective Practitioner. Basic Books, New York, 1983.

38. Simon, H. The structure of ill-structured problems. Artif. Intell., 4 (1973), 181-201.

39. STAR, S. L. Scientific theories as going concerns: The development of the localizationist perspective in neurophysiology, 1870-1906. Ph.D. dissertation, Dept. of Social and Behavioral Science, Univ. of California, San Francisco, 1983.

40. StaR, S. L. Simplification in scientific work: An example from neuroscience research. Social Studies of Science, 13 (1983), 205-228.

41. STAR, S. L. Tradeoffs in scientific work: Report on a robotics design project. Presented to the ACM, San Francisco, October, 1984.

42. STAR, S. L. Scientific work and uncertainty. Social Studies of Science, 15 (1985), 391-427.

43. STAR, S. L. Articulation work and discretion. Report submitted to the MIT Artificial Intelligence Lab, 1985.

44. STAR, S. L. Triangulating clinical and basic research: British localizationists, 1870-1906. History of Science, 24 (1986), 29-48.

45. STAR, S. L., AND Gerson, E. M. The management and dynamics of anomalies in scientific research, The Sociological Quarterly, forthcoming. 
46. Strauss, A. L. Professions, Work and Careers. Transaction Books, New Brunswick, N.J., 1975.

47. Strauss, A. L. Negotiations. Jossey-Bass, San Francisco, 1978.

48. Strauss, A. L. Work and the division of labor. The Sociol. Quart., 26 (1985), 1-19.

49. STRauss, A. L. Articulation work, The Sociological Quarterly, forthcominig.

50. Strauss, A. L., Fagerhaugh, S., Wiener, C., And Suzcer, B. The Social Organization of Medical Work. University of Chicago Press, Chicago, 1984.

Received February 1986; revised June 1986; accepted June 1986 